\title{
ANALISIS PEMASARAN BUAH NAGA DI DESA SUNGAI KURUK 3 KECAMATAN SUERUWAY KABUPATEN ACEH TAMIANG
}

\author{
Thursina Mahyuddin ${ }^{1}$, Supristiwendi ${ }^{2}$ dan Nurhasanah ${ }^{2}$ \\ ${ }^{I}$ Dosen Fakultas Pertanian Universitas Samudra \\ ${ }^{2}$ Dosen Fakultas Pertanian Universitas Samudra \\ ${ }^{2}$ Mahasiswa Program Studi Agribisnis Fakultas Pertanian Universitas Samudra
}

\begin{abstract}
ABSTRAK
Tujuan penelitian untuk mengetahui pola saluran, margin, biaya, farmer's share dan efisiensi pemasaran buah naga di Desa Sungai Kuruk 3 Kecamatan Seuruway Kabupaten Aceh Tamiang. Penelitian ini menggunakan metode survei. Objek penelitian adalah petani buah naga dan lembaga pemasaran buah naga di di Desa Sungai Kuruk 3 Kecamatan Seuruway Kabupaten Aceh Tamiang. Rung lingkup meliputi pola saluran, margin, biaya, farmer's share dan efisiensi pemasaran buah naga di Desa Sungai Kuruk 3 Kecamatan Seuruway Kabupaten Aceh Tamiang. Penelitian dilaksanakan pada bulan Mei s/d Juni 2018.

Hasil penelitian Karakteristik rata-rata umur petani sampel usahatani buah naga di Desa Sungai Kuruk 3 Kecamatan Seuruway adalah 40,33 tahun, petani sampel rata-rata 9,40 tahun, rata-rata jumlah tanggungan keluarga sebanyak 4 orang dan rata-rata pengalaman petani sampel dalam usahatani buah naga sebesar 9,03 tahun. Rata-rata umur agen dan pedagang buah naga di Desa Sungai Kuruk 3 Kecamatan Seuruway adalah 40,25 tahun, tingkat pendidikan 12,75 tahun, jumlah tanggungan keluarga rata-rata 3 orang, dan pengalaman dibidang berdagang rata-rata 7,00 tahun. Ada 3 saluran pemasaran buah naga di Desa Sungai Kuruk 3. Saluran pemasaran yang paling banyak digunakan petani adalah saluran pemasaran III yaitu sebanyak tiga belas orang $(43,33 \%)$ dimana petani langsung menjual buah naganya kepada pedagang pengecer. Selanjutnya saluran II sebanyak sembilan orang $(30,00 \%)$ dan saluaran I sebanyak delapan orang $(26,67 \%)$. Rata-rata biaya pemasaran buah naga pada saluran pemasaran I yaitu sebesar Rp.2.050,00/Kg, saluran II sebesar 1.950,00/Kg dan saluran III sebesar Rp. 850,00/Kg. Margin pemasaran buah naga pada saluran I sebesar Rp. $7.875,00 / \mathrm{Kg}$, margin pemasaran pada saluran II sebesar Rp. 5.000,00/Kg dan margin pemasaran pada saluran III sebesar Rp. $4.683,33 / \mathrm{Kg}$. Farmer's share pada saluran I sebesar $61,31 \%$, saluaran II sebesar 74,27\% dan saluran III sebesar $86,59 \%$. Saluran pemasaran I memiliki nilai efisiensi pemasaran sebesar $10,07 \%$, saluran II sebesar $10,03 \%$ dan saluran III sebesar 4,56\%. Saluran tiga (III) merupakan saluran pemasaran yang paling efisien karena memiliki nilai efisiensi yang paling kecil dibanding saluran I dan saluran II di Desa Kuruk 3 Kecamatan Seuruway Kabupaten Aceh Tamiang.
\end{abstract}

Kata Kunci: Pemasaran, Buah Naga, Saluran, Margin, Efisiensi

\section{PENDAHULUAN}

Kecamatan Seruway merupakan salah satu kecamatan yang berada di Kabupaten Aceh Tamiang yang merupakan penghasil komoditi buah naga untuk memenuhi kebutuhan masyarakat daerah sekitarnya. Desa yang mengembangkan buah naga secara luas di Kecamatan Seruway adalah Desa Sungai Kuruk 3. Secara keseluruhan hanya 4 dusun yang terdapat tanaman buah naga di Desa Sungai Kuruk 3 yaitu; Dusun Bakti, Dusun Tengah, Dusun Keluarga dan Dusun Depan.

Teori pemasaran yang amat sederhana pun selalu menekankan bahwa 
dalam kegiatan pemasaran harus jelas siapa yang menjual apa, dimana, bagaimana, bilamana, dalam jumlah berapa dan kepada siapa. Adanya strategi yang tepat akan sangat mendukung kegiatan pemasaran secara keseluruhan. Definisi menurut Harper W (2000:4) bahwa Pemasaran adalah "Suatu proses sosial yang melibatkan kegiatankegiatan penting yang memungkinkan indidvidu dan perusahaan mendapatkan apa yang mereka butuhkan dan inginkan melalui pertukaran dengan pihak lain dan untuk mengembangkan hubungan pertukaran".

Faktor yang penting dalam memperlancar arus barang dari produsen ke konsumen adalah pemilihan saluran pemasaran yang tepat. Pemasaran adalah salah satu kegiatan yang dilakukan petani untuk mempertahankan kelangsungan usahataninya, dalam hal ini kegiatan jual beli untuk memperoleh keuntungan, sehingga setiap pemasaran diperlukan analisis yang bertujuan untuk mengetahui efisien atau tidaknya suatu saluran pemasaran tersebut.

Saluran pemasaran antara satu dengan bagian lainnya merupakan satu kesatuan yang saling berkaitan sehingga masing-masing lembaga tersebut mendapatkan bagian harga masing-masing. Dalam kegiatan pemasaran yang dilakukan disetiap lembaga pemasaran, tentu membutuhkan biaya pemasaran. Biaya pemasaran dikeluarkan untuk menjual produk yang telah dihasilkan oleh produsen agara produk yang telah dihasilkan dapat sampai ke konsumen.

Panjang pendeknya suatu
saluran
mempengaruhi marginnya, semakin panjangsaluran pemasaran yang digunakan maka semakin besar pula margin pemasarannya. Bagian harga yang diterima masing-masing lembaga pemasaran apabila pembagiannya adil dari keseluruhan harga yang dibayar konsumen akhir dari semua pihak yang ikut serta didalam seluruh kegiatan produksi dan pemasaran barang itu maka saluran pemasaran tersebut disebut efisien. Berdasarkan uraian pada latar belakang di atas penulis mersa penting dan ingin meneliti tentang analisis pemasaran buah naga di Desa Sungai Kuruk 3 Kecamatan Seruway Kabupaten Aceh Tamiang.

\section{Identifikasi Masalah}

1. Bagaimana pola saluran, biaya, margin dan farmer's share pada pemasaran buah naga di Desa Sungai Kuruk 3 Kecamatan Seruway Kabupaten Aceh Tamiang?

2. Apakah pemasaran buah naga di Desa Sungai Kuruk 3 Kecamatan Seruway Kabupaten Aceh Tamiang sudah efisien?

\section{Tujuan Penelitian}

1. Untuk menganalisis pola saluran, biaya, margin dan farmer's share pada pemasaran buah naga di Desa Sungai Kuruk 3 Kecamatan Seruway Kabupaten Aceh Tamiang.

2. Untuk menganalisis efisiensi pemasaran buah naga di Desa Sungai Kuruk 3 Kecamatan Seruway Kabupaten Aceh Tamiang.

\section{Hipotesis Penelitian}

"Pemasaran buah naga di Desa Sungai Kuruk 3 Kecamatan Seruway Kabupaten Aceh Tamiang sudah efisien".

\section{METODOLOGI PENELITIAN Metode, Lokasi, Objek, Ruang Lingkup dan Waktu Penelitian}

Penelitian ini menggunakan metode survei. Objek penelitian adalah petani buah naga dan lembaga pemasaran buah naga di di Desa Sungai Kuruk 3 Kecamatan Seuruway Kabupaten Aceh 
Tamiang. Rung lingkup meliputi pola saluran, margin, biaya, farmer's share dan efisiensi pemasaran buah naga di Desa Sungai Kuruk 3 Kecamatan Seuruway Kabupaten Aceh Tamiang. Penelitian dilaksanakan pada bulan Mei s/d Juni 2018.

\section{Teknik Penentuan Sampel Penelitian}

Populasi dalam penelitian ini terdiri dari 2 (dua) kelompok yaitu petani buah naga dan populasi pedagang (lembaga pemasaran) buah naga yang terlibat dalam pemasaran buah naga di lokasi penelitian. Menurut Nana Tabel III-1. Jumlah Populasi dan Sampel Petani Buah Naga Di Desa Sungai Kuruk 3 Kecamatan Seruway, 2108

\begin{tabular}{|c|l|r|r|}
\hline No & \multicolumn{1}{|c|}{ Dusun } & Populasi (Orang) & Sampel (Orang) \\
\hline 1 & Bakti & 12 & 12 \\
2 & Tengah & 8 & 8 \\
3 & Keluarga & 6 & 6 \\
4 & Depan & 4 & 4 \\
\hline \multicolumn{2}{|c|}{ Jumlah } & 30 & 30 \\
\hline
\end{tabular}

Sumber: BPPPL Seruway, 2018

Dari Tabel III-1 di atas dilihat bahwa jumlah populasi petani buah naga di Desa Sungai Kuruk 3 Kecamatan Seruway sebanyak 30 orang petani buah naga yang tersebar di Dusun Bakti 12 orang, Dusun
(2005:5),'Sampel merupakan sebagian dari populasi yang paling tidak mempunyai ciri yang sama dengan populasinya untuk mewakili populasi yang ada".

Pengambilan sampel petani buah naga dan lembaga pemasaran buah naga dilakukan dengan metode full sampling (sensus). Sampel sensus adalah dimana semua anggota populasi dijadikan sampel (Sugiyono, 2008:124). Untuk lebih jelas jumlah populasi dan sampel petani buah naga masing-masing desa sampel dapat dilihat pada tabel III-1 berikut.
Tengah 8 orang, Dusun Keluarga 6 orang dan Dusun Depan 4 orang.

Adapun jumlah lembaga pemasaran buah naga di Di Desa Sungai Kuruk 3 Kecamatan Seruway Kabupaten

\section{Aceh Tamiang adalah sebagai berikut.}

Tabel III-2. Jumlah Populasi dan Sampel Lembaga Pemasaran Buah Naga Di Desa Sungai Kuruk 3 Kecamatan Seruway, 2108

\begin{tabular}{|c|l|c|c|}
\hline No & Lembaga Pemasaran & Populasi (Orang) & Sampel (Orang) \\
\hline 1 & Pedagang Desa & 3 & 3 \\
2 & Pedagang Kecamatan & 5 & 5 \\
3 & Pedagang Pengecer & 8 & 8 \\
\hline \multicolumn{2}{|l|}{ Jumlah } & 16 & 16 \\
\hline
\end{tabular}

Sumber: Data Primer (diolah), 2018

Tabel III-2 menjelaskan bahwa jumlah populasi dan sampel lembaga pemasaran sebanyak 16 orang terdiri dari 3 orang pedagang pengumpul desa, 5 orang pedagang pengumpul kecamatan dan 8 orang pedagang pengecer.
Sumber data penelitian merupakan faktor penting yang menjadi pertimbangan dalam menentukan metode pengumpulan data. Data yang digunakan dalam penelitian ini dapat dibagi menjadi dua jenis berdasarkan pada pengelompokkan yaitu:

\section{Pengumpulan Data}


a) Data primer adalah data yang diperoleh secara langsung dari responden sebagai nara sumber melalui cara; Observasi, wawancara dan kuisioner.

b) Data sekunder adalah data yang diambil dengan pendokumentasian data yang telah ada di daerah penelitian, instansi terkait, buku, jurnal, laporan dan sumber media massa yang berkaitan dengan penelitian.

\section{Variabel Data Yang Dianalisis}

a. Saluran Pemasaran

(Bentuk/Tipe Saluran Pemasaran)

b. Biaya Pemasaran $(\mathrm{Rp} / \mathrm{Kg})$

c. Farmer Share (\%)

d. Margin Pemasaran $(\mathrm{Rp} / \mathrm{Kg})$

e. Efisiensi Pemasaran(\%)

\section{Metode Analisis dan Pengujian}

Hipotesis

Saluran Pemasaran

Untuk mengetahui pola (bentuk) saluran pemasaran buah naga di Desa Sungai Kuruk 3 Kecamatan Seruway Kabupaten Aceh Tamiang dilakukan dengan cara deskriptif kualitatif yaitu dengan cara menjelaskan bentuk-bentuk saluran pemasaran buah naga di Desa Sungai Kuruk 3 Kecamatan Seruway Kabupaten Aceh Tamiang.

\section{Biaya Pemasaran}

Untuk menghitung besarnya biaya pemasaran buah naga ialah dengan menjumlahkan semua biaya yang dikeluarkan oleh setiap lembaga pemasaran yang terlibat (Sudiyono, 2002:39) :

$\mathrm{Bp}=\mathrm{Bp} 1+$

$\mathrm{Bp} 2+$

..........Bpn

Keterangan

Bp : Biaya Pemasaran Buah naga $(\mathrm{Rp} / \mathrm{Kg})$

Bp1, Bp2...Bpn : Biaya pemasaran pada tiap lembaga pemasaran buah naga $(\mathrm{Rp} / \mathrm{Kg})$

\section{Farmer'sShare}

Untuk menghitung Farmer's share menggunakan rumus sebagai berikut (Hudson dalam Alham, 2013:22):

$\mathrm{FS}=\mathrm{Pf} / \operatorname{Pr} \times 100 \%$

Dimana :

FS = Farmer's share ditingkat petani

$(\%)$

$\mathrm{Pf}_{\mathrm{f}} \quad=$ Harga buah naga ditingkat

petani $(\mathrm{Rp} / \mathrm{Kg})$

$\mathrm{Pr} \quad=$ Harga buah naga ditingkat

pengecer $(\mathrm{Rp} / \mathrm{Kg})$

Kaidah pengambilan keputusan efesiensi pemasaran ini adalah :

- Fs < 50\% maka saluran pemasaran tidak efesien dan memihak kepada petani buah naga

- Fs < 50\% maka saluran pemasaran tidak efesien dan memihak kepada petani buah naga

\section{Margin Pemasaran}

Untuk menghitung margin

pemasaran pisang dapat diketahui dengan rumus sebagai berikut (Hudson dalam Alham, 2013:22) :

$\mathrm{M}=\mathrm{Pr}-\mathrm{Pf}$

Dimana:

$\mathrm{M} \quad=$ Margin total pemasaran setiap saluran pemasaran

$\mathrm{Pr}_{\mathrm{r}} \quad=$ Harga eceran pisang di pasar konsumen $(\mathrm{Rp} / \mathrm{Kg})$

Pf $=$ Harga pisang di tingkat petani $(\mathrm{Rp} / \mathrm{Kg})$

Kaidah pengambilan keputusan margin pemasaran ini adalah :

- Jika perbedaan antara harga yang diterima produsen dengan harga yang diterima konsumen tinggi maka margin pemasaran tinggi.

- Jika perbedaan antara harga yang diterima produsen dengan harga yang diterima konsumen rendah maka margin pemasaran rendah.

\section{Efisiensi Pemasaran}


Efisiensi pemasaran adalah nisbah antara biaya pemasaran dengan nilai produk yang dijual, dinyatakan dengan persen. Rumus untuk Efesiensi pemasaran adalah sebagai berikut

$\mathrm{Ep}=\mathrm{BP} / \mathrm{HE} \times 100 \%$

Dimana:

Ep = Efisiensi pemasaran

$\mathrm{BP}=$ Biaya pemasaran

$\mathrm{HE}=$ Harga eceran

Kaidah pengambilan keputusan efesiensi pemasaran ini adalah :

Tabel V-1. Karakteristik Petani Sampel di Desa Sungai Kuruk 3 Kecamatan Seuruway, 2018
- $\quad$ Ep $<50 \%$ maka saluran pemasaran efesien

- $\quad$ Ep > 50\% maka saluran pemasaran tidak efesien

\section{HASIL DAN PEMBAHASAN \\ Karakteristik Petani dan Pedagang}

Untuk lebih jelasnya mengenai keadaan karakteristik petani sampel di Desa Sungai Kuruk 3 Kecamatan Seuruway dapat dilihat pada tabel V-1 berikut.

Sumber: Data Primer (diolah), 2018

Tabel V-1 di atas dapat dilihat bahwa rata-rata umur petani sampel usahatani buah naga di Desa Sungai Kuruk 3 Kecamatan Seuruway adalah 40,33 tahun, pendidikan petani sampel rata-rata 9,40 tahun, rata-rata jumlah tanggungan keluarga sebanyak 4 orang dan rata-rata pengalaman petani sampel dalam usahatani buah naga sebesar 9,03

tahun menunjukkan keahlian dan keterampilan yang dimiliki oleh seorang tergolong baik.

Sedangkan untuk melihat karakteristik agen dan pedagang sampel di Desa Sungai Kuruk 3 Kecamatan Seuruway Peureulak dapat dilihat pada tabel V-2 berikut.

Tabel V-2. Rata-rata Karakteristik Lembaga Pemasaran Buah naga di Desa Sungai Kuruk 3 Kecamatan Seuruway, 2018

\begin{tabular}{|c|c|c|c|c|c|}
\hline No & Pedagang & $\begin{array}{l}\text { Umur } \\
\text { (Tahun) }\end{array}$ & $\begin{array}{l}\text { Pendidikan } \\
\text { (Tahun) }\end{array}$ & $\begin{array}{l}\text { Pengalaman } \\
\text { (Tahun) }\end{array}$ & $\begin{array}{c}\text { Jumlah Tanggungan } \\
\text { (Orang) }\end{array}$ \\
\hline 1 & $\begin{array}{l}\text { Pedagang Desa } \\
\text { Pedagang }\end{array}$ & 41,33 & 13,00 & 7,33 & 3,00 \\
\hline 2 & Kecamatan & 41,80 & 13,80 & 7,40 & 3,00 \\
\hline 3 & Pedagang Pengecer & 38,88 & 12,00 & 6,63 & 3,00 \\
\hline & Rata-Rata & 40,25 & 12,75 & 7,00 & 3,00 \\
\hline
\end{tabular}

Sumber: Data Primer (diolah), 2018

Berdasarkan tabel V-2 di atas terlihat bahwa rata-rata umur agen dan pedagang buah nagadi Desa Sungai Kuruk 3 Kecamatan Seuruway adalah 40,25 tahun, tingkat pendidikan 12,75 tahun,

jumlah tanggungan keluarga rata-rata 3 orang, dan pengalaman dibidang berdagang rata-rata 7,00 tahun.

Saluran Pemasaran Buah Naga 
Dapat dijelaskan bahwa pola saluran pemasaran buah naga di Desa Sungai Kuruk 3 Kecamatan Seuruway terdiri dari tiga pola saluran pemasaran, yaitu sebagai berikut:

1. Saluran I: Petani $\rightarrow$ Pedagang Desa $\rightarrow$ Pedagang $\rightarrow$ Pedagang Kecamatan $\rightarrow$ Konsumen
2. Saluran II: Petani $\rightarrow$ Pedagang Kecamatan $\rightarrow$ Pedagang Pengecer $\rightarrow$ Konsumen

3. Saluran III: Petani $\rightarrow$ Pedagang Pengecer $\rightarrow$ Konsumen

Adapun jumlah petani berdasarkan saluran pemasaran buah naga yang digunakan dalam mendistribusikan buah naga dapat dilihat pada tabel V-3 berikut.

Tabel V-3. Pola Saluran dan Jumlah Petani Buah Naga di Desa Sungai Kuruk 3 Kecamatan Seuruway, 2018

\begin{tabular}{|c|c|c|c|}
\hline No & Saluran & Jumlah Petani (orang) & Persentase (\%) \\
\hline 1 & I & 8 & 26,67 \\
\hline 2 & II & 9 & 30,00 \\
\hline 3 & III & 13 & 43,33 \\
\hline \multicolumn{2}{|c|}{ Total } & 30 & 100,00 \\
\hline
\end{tabular}

Sumber: Data Primer (diolah), 2018

Berdasarkan tabel V-3 di atas dapat dilihat bahwa saluran pemasaran yang paling banyak digunakan petani adalah saluran pemasaran III yaitu sebanyak tiga belas orang $(43,33 \%)$ dimana petani langsung menjual buah naganya kepada pedagang pengecer. Selanjutnya saluran II sebanyak sembilan orang $(30,00 \%)$ dan saluaran I sebanyak delapan orang (26,67\%). Saluran pemasaran III paling banyak digunakan oleh petani karena harga jual buah naga lebih tinggi pada saluran ini dibandingkan dengan saluran I dan II, hal ini diakibatkan karena lembaga pemasaran yang digunakan tidak terlalu

panjang sehingga keuntungan yang diperoleh petani lebih banyak dibandingkan dengan menggunakan saluaran I dan II karena perbedaan antara harga yang diterima produsen dengan harga yang diterima konsumen tinggi, hal ini diakibatkan karena panjangnya lembaga pemasaran yang digunakan.

\section{Biaya Pemasaran}

Untuk melihat rata-rata penggunaan biaya pemasaran buah naga di Desa Sungai Kuruk 3 Kecamatan Seuruway dapat dilihat pada tabel V-4 berikut.

Tabel V-4. Rata-rata Biaya Pemasaran Buah Naga di Desa Sungai Kuruk 3 Kecamatan Seuruway Kabupaten Aceh Tamiang, 2018

\begin{tabular}{|c|c|c|}
\hline \multicolumn{1}{|l|}{ No } & Saluran & Biaya Pemasaran $(\mathrm{Rp} / \mathrm{Kg})$ \\
\hline 1 & I & $2.050,00$ \\
\hline 2 & II & $1.950,00$ \\
\hline 3 & III & 850,00 \\
\hline
\end{tabular}

Sumber: Lampiran 6

Berdasarkan tabel V-4 di atas dapat dilihat bahwa rata-rata biaya pemasaran buah naga pada saluran pemasaran I yaitu sebesar Rp.2.050,00/Kg, saluran II sebesar $1.950,00 / \mathrm{Kg}$ dan saluran III sebesar Rp.
$850,00 / \mathrm{Kg}$. Biaya pemasaran pada saluran III lebih kecil dibandingkan dengan biaya pemasaran pada saluran I dan II karena saluran pemasaran yang terlibat pada saluran pemasaran III tersebut hanya satu yaitu pedagang 
pengecer jadi biaya pemasaran yang dikeluarkan jauh lebih kecil.

\section{Margin Pemasaran}

Untuk lebih jelasnya mengenai rata-rata margin pemasaran buah naga pada saluran pemasaran I, II dan III di Desa Sungai Kuruk 3 Kecamatan Seuruway dapat dilihat pada tabel V-5 berikut.

Tabel V-5. Rata-rata Margin Pemasaran Buah naga pada Saluran I, II dan III di Desa Sungai Kuruk 3 Kecamatan Seuruway, 2018

\begin{tabular}{|c|c|r|r|r|}
\hline No & Saluran & $\begin{array}{c}\text { Harga Tingkat Petani } \\
(\mathrm{Rp} / \mathrm{Kg})\end{array}$ & $\begin{array}{c}\text { Harga Tingkat } \\
\text { Konsumen }(\mathrm{Rp} / \mathrm{Kg})\end{array}$ & Margin $(\mathrm{Rp} / \mathrm{Kg})$ \\
\hline 1 & I & $12.500,00$ & $20.375,00$ & $7.875,00$ \\
2 & II & $14.444,44$ & $19.444,44$ & $5.000,00$ \\
3 & III & $16.153,85$ & $18.653,85$ & $2.500,00$ \\
\hline \multicolumn{2}{|r|}{ Rata-Rata } & $14.666,67$ & $19.350,00$ & $4.683,33$ \\
\hline
\end{tabular}

Sumber: Data Primer (diolah), 2018

Berdasarkan tabel V-5 di atas dapat dilihat bahwa margin pemasaran buah naga pada saluran I sebesar Rp. $7.875,00 / \mathrm{Kg}$, margin pemasaran pada saluran II sebesar Rp. 5.000,00/Kg dan margin pemasaran pada saluran III sebesar Rp. 4.683,33/Kg. Dari sisi margin pemasaran dapat diketahui bahwa saluran III merupakan saluran yang paling efisien karena mempunyai margin pemasaran yang paling kecil

dibandingkan dengan mergin pemasaran pada saluran I dan saluran II. Artinya selisih antara harga ditingkat petani dengan harga ditingkat konsumen paling kecil terjadi pada saluran III.

\section{Farmer's Share}

Berikut ini gambaran besarnya bagian harga yang diterima oleh petani pada setiap lembaga pemasaran buah naga.

Tabel V-6. Rata-rata Besarnya Farmer's Share pada Setiap Lembaga Pemasaran Buah Naga di Desa Sungai Kuruk 3 Kecamatan Seuruway, 2018

\begin{tabular}{|c|c|c|c|c|}
\hline No & Saluran & $\begin{array}{c}\text { Biaya Pemasaran } \\
(\mathrm{Rp} / \mathrm{Kg})\end{array}$ & $\begin{array}{c}\text { Harga Tingkat Konsumen } \\
(\mathrm{Rp} / \mathrm{Kg})\end{array}$ & Farmer's Share (\%) \\
\hline 1 & I & $12.500,00$ & $20.375,00$ & 61,31 \\
2 & II & $14.444,44$ & $19.444,44$ & 74,27 \\
3 & III & $16.153,85$ & $18.653,85$ & 86,59 \\
\hline \multicolumn{2}{|c|}{ Rata-Rata } & $14.666,67$ & $19.350,00$ & 76,16 \\
\hline
\end{tabular}

Sumber: Data Primer (diolah), 2018

Berdasarkan tabel V-6 di atas dapat dilihat bahwa farmer's share pada saluran I sebesar $61,31 \%$, saluaran II sebesar $74,27 \%$ dan saluran III sebesar $86,59 \%$. Dengan demikian dari sisi farmer's share saluran III merupakan saluran yang paling efisien karena petani menerima bagian harga yang paling besar dibanding saluran I dan saluran III. Dalam hal ini petani menerima harga yang paling tinggi pada saluran III sehingga secara langsung berakibat meningkatnya penerimaan dan pendapatan petani buah naga di Desa Kuruk 3 Kecamatan Seuruway Kabupaten Aceh Tamiang. 


\section{Efesiensi Pemasaran}

Untuk lebih jelasnya mengenai efisiensi pemasaran buah naga di Desa Tabel V-7. Efisiensi Pemasaran Buah naga di Desa Sungai Kuruk 3 Kecamatan Seuruway, 2018.

\begin{tabular}{|c|c|c|c|r|}
\hline No & Saluran & $\begin{array}{c}\text { Biaya Pemasaran } \\
(\mathrm{Rp} / \mathrm{Kg})\end{array}$ & $\begin{array}{c}\text { Harga Tingkat } \\
\text { Konsumen }(\mathrm{Rp} / \mathrm{Kg})\end{array}$ & Efisiensi (\%) \\
\hline 1 & 1 & $2.050,00$ & $20.375,00$ & 10,07 \\
2 & 2 & $1.950,00$ & $19.444,44$ & 10,03 \\
3 & 3 & 850,00 & $18.653,85$ & 4,56 \\
\hline \multicolumn{2}{|c|}{ Rata-Rata } & $1.500,00$ & $19.350,00$ & 7,67 \\
\hline
\end{tabular}

Sumber: Data Primer (diolah), 2018

Berdasarkan tabel V-10 di atas dapat dilihat bahwa saluran pemasaran I memiliki nilai efisiensi pemasaran sebesar $10,07 \%$, saluran II sebesar $10,03 \%$ dan saluran III sebesar $4,56 \%$. Ketiga saluran pemasaran buah naga di Desa Sungai Kuruk 3 Kecamatan Seuruway dikatakan efisien karena berada dibawah 50\%. Namun dari ketiga saluran pemasaran tersebut, saluran tiga (III) merupakan saluran pemasaran yang paling efisien karena memiliki nilai efisiensi yang paling kecil dibanding saluran I dan saluran II di Desa Kuruk 3 Kecamatan Seuruway Kabupaten Aceh Tamiang. Hal ini sesuai dengan kaidah pengambilan keputusan efisiensi pemasaran yaitu jika Ep < 50\% maka saluran pemasaran tersebut dikatakan efisien, dan jika Ep > 50\% maka saluran pemasaran tersebut dikatakan tidak efisien.

Meskipun saluran pemasaran III merupakan saluran pemasaran yang paling efisien, namun tidak semua petani buah naga dapat memilih/menggunakan saluran ini (saluran III). Hal ini diakibatkan oleh beberapa faktor antara lain kondisi jalan dan jembatan yang masih sangat kurang memadai. Petani yang paling banyak menggunakan saluran III ialah petani yang usahatani buah naganya berada di dekat dengan pedagang pengecer serta memiliki alat transportasi yang memadai.
Kuruk 3 Kecamatan Seuruway Kabupaten Aceh Tamiang dapat dilihat pada tabel V7 berikut ini. 
10,07\%, saluran II sebesar $10,03 \%$ dan saluran III sebesar $4,56 \%$.

6. Saluran tiga (III) merupakan saluran pemasaran yang paling efisien karena memiliki nilai efisiensi yang paling kecil dibanding saluran I dan saluran II di Desa Kuruk 3 Kecamatan Seuruway Kabupaten Aceh Tamiang.

\subsection{Saran-saran}

1. Diharapkan petani dapat menggunakan saluran tiga (III) merupakan saluran pemasaran yang paling efisien karena memiliki nilai efisiensi yang paling kecil dibanding saluran I dan saluran II di Desa Kuruk 3 Kecamatan Seuruway Kabupaten Aceh Tamiang.

Diharapkan petani dapat menggunakan saluran tiga (III) merupakan saluran pemasaran yang paling besar memberikan bagian harga kepada petani buah naga dibanding saluran I dan saluran II di Desa Kuruk 3 Kecamatan Seuruway Kabupaten Aceh Tamiang.

\section{DAFTAR PUSTAKA}

Anonim, 2017. Potensi Wilayah BPPK Kecamatan Seuruway Tahun 2016. Seuruway. Kuala Simpang

Anonim, 2017. Aceh Tamiang Dalam Angka Tahun 2016. Kuala Simpang. Aceh Tamiang

Daniel, M., 2002. Pengantar Ekonomi Pertanian. Bumi Aksara. Jakarta

Gitosudarmo, I. 2001. Manajemen Pemasaran. BPFE. Yokyakarta

Hanafiah dan Saefuddin A, M,. 2000. Tata Niaga Hasil Pertanian. UI Press. Jakarta
Limbong dan Sitorus, 2005. Pengantar Tataniaga Pertanian. FP IPB. Bogor

Mangdeska, 2009. Analisis Pendapatan Usahatani dan Faktor-Faktor Yang Mempengaruhinya. Penebar Swadaya. Jakarta

Mubyarto. 2002. Pengantar Ekonomi Pertanian. LP3S. Jakarta

Nazir, M. 2005. Metode Penelitian. Ghalia Indonesia. Jakarta

Rahim A dan Hastuti R. 2007. Pengantar Teori dan Kasus Ekonomi Pertanian. Penebar Swadaya. Jakarta

Sekaran U, 2006. Metode Penelitian. Ghalia Indonesia. Jakarta

Soekartawi., 2002. Prinsip Dasar Manajemen Pemasaran HasilHasil Pertanian. Raja Grafindo Persada. Jakarta

Sudjana, Nana. 2005. Tuntunan Penyusunan Karya Ilmiah. FMIPA. Bandung

Sugiyono, 2008. Metode Penelitian Bisnis dan Aplikasi. Alfabeta. Bandung

Sulvadewi, 2000. Manajemen Pemasaran: Kasus dan Solusi. Kanisius. Jakarta

Winandi R. Asmarantika. 2009. Pemasaran Produk-Produk Pertanian. Bunga Rampai Agribisnis Seri Pemasaran. Dept Agribisnis Fakultas Ekonomi dan Manajemen, IPB. Bogor

Winandi R. Asmarantika. 2014. Pemasaran Produk-Produk Pertanian. Bunga Rampai Agribisnis Seri Pemasaran. Dept Agribisnis Fakultas Ekonomi dan Manajemen, IPB. Bogor

Yuliarti N. 2012. Bisnis Buah Naga. IPB Press. Bogor 